\title{
Amaryllidaceae plants: a potential natural resource for the treatment of Chagas disease
}

\author{
Nieves Martínez-Peinado ${ }^{1}$, Nuria Cortes-Serra', Luciana R. Tallini ${ }^{2,3}$, Maria-Jesus Pinazo ${ }^{1}$, Joaquim Gascon', \\ Jaume Bastida ${ }^{2^{*}}$ and Julio Alonso-Padilla ${ }^{{ }^{*}}$ (1)
}

\begin{abstract}
Background: Chagas disease is a neglected zoonosis caused by the parasite Trypanosoma cruzi. It affects over six million people, mostly in Latin America. Drugs available to treat T. cruzi infection have associated toxicity and questionable efficacy at the chronic stage. Hence, the discovery of more effective and safer drugs is an unmet medical need. For this, natural products represent a pool of unique chemical diversity that can serve as excellent templates for the synthesis of active molecules.
\end{abstract}

Methods: A collection of 79 extracts of Amaryllidaceae plants were screened against T. cruzi. Active extracts against the parasite were progressed through two cell toxicity assays based on Vero and HepG2 cells to determine their selectivity profile and discard those toxic to host cells. Anti-T. cruzi-specific extracts were further qualified by an antiamastigote stage assay.

Results: Two extracts, respectively from Crinum erubescens and Rhodophiala andicola, were identified as highly active and specific against T. cruzi and its mammalian replicative form.

Conclusions: The results retrieved in this study encourage further exploration of the chemical content of these extracts in search of new anti-T. cruzi drug development starting points.

Keywords: Chagas disease, Trypanosoma cruzi, Amaryllidaceae, Extracts, Phenotypic assays, Cytotoxicity

\section{Background}

The parasite Trypanosoma cruzi is the etiological agent of Chagas disease, a debilitating zoonosis affecting over six million people worldwide [1]. It was discovered over 110 years ago, but remains an important public health problem in Latin America, where it exerts its highest burden [1]. In the past few decades, the disease impact has been globalized to non-endemic regions due to population movement [2].

\footnotetext{
*Correspondence: jaumebastida@ub.edu; julio.a.padilla@isglobal.org ${ }^{1}$ Barcelona Institute for Global Health (ISGlobal), Hospital Clinic-University of Barcelona, 08036 Barcelona, Spain

${ }^{2}$ Departament de Biologia, Sanitat i Medi Ambient, Facultat de Farmàcia I Ciències de L'Alimentació, Universitat de Barcelona, 08028 Barcelona, Spain

Full list of author information is available at the end of the article
}

In the disease course, there is first an acute phase that goes undiagnosed and untreated because it is mostly asymptomatic. Without treatment, however, it evolves to an indeterminate chronic phase throughout which about $30 \%$ of those chronically infected will develop damage to cardiac and/or digestive tissues, which can lead to death [3].

There is no vaccine available, but there are two chemotherapeutic treatments for T. cruzi infection: benznidazole (BNZ) and nifurtimox (NFX). Both have good efficacy when administered early after infection and are well tolerated by infants. However, at the chronic stage, which is when a diagnosis is usually obtained, their efficacy diminishes [3], and the appearance of toxic side effects is common [4]. In addition, treatment response may vary according to the parasite strain, and drug resistance has been observed [5]. Thus, safer and more 
efficacious drugs for the treatment of Chagas disease are needed.

Upon clinical failure of azoles (posaconazole and E1224) [6], the pipeline of new chemical entities under clinical trial is limited to fexinidazole [7] and amiodarone [8]. Most presently ongoing trials are based on the evaluation of alternative regimens and doses of already known drugs $[4,9]$, so new chemical entities would be very welcome in the field. For this purpose, natural products represent a rich source of biologically active substances [10-12]. They offer a wealth of bio-structural information that can be used to guide drug discovery and molecular design [10-12]. In fact, around $60 \%$ of the drugs available nowadays derive from natural products [13].

In an attempt to find potential therapies for Chagas disease, the search for new compounds extracted from plants has intensified in the past decade [14]. Almost 400 species belonging to more than 100 plant families have been evaluated against T. cruzi [14]. Most of the reports have studied the activity of isolated alkaloids, flavonoids, cathechins, lignans, diterpenes and sesquiterpenes [14]. The extraction process for these chemical entities can involve the use of one or more solvents, as well as a single and/or various parts of the plant. Usually, the parts of the plants evaluated are the ones used in traditional treatments or those described to carry higher concentrations of the known active compounds [14].

Recently, members of the family Amaryllidaceae have attracted considerable attention due to their alkaloid composition, with unique structural features and multiple types of biological activity $[15,16]$. Isoquinoline-type alkaloids found in Amaryllidaceae plants are classified into eight groups: galanthamine, lycorine, crinine, haemanthamine, homolycorine, narciclasine, tazettine and montanine [16]. Each plant species produces a different mixture of alkaloids due to differential expression of the required biosynthetic enzymes, which have their own substrate specificity [17]. Moreover, variation in the alkaloid composition has been observed within the same plant species collected from different locations [18], and between different biological tissues of the same plant [15]. Amaryllidaceae plants have been used as part of traditional treatments of fever, swelling, cancer or malaria for centuries [19]. They have subsequently been studied for their potential application as a source of anticancer, anti-inflammatory, antimicrobial and anticholinesterase activity [15]. In fact, Amaryllidaceae alkaloid galanthamine, an acetylcholinesterase inhibitor, received approval by the Food and Drug Administration to treat Alzheimer's disease [20]. Thinking of their anti-parasitic use, some Amaryllidaceae alkaloids have shown promising results against Plasmodium falciparum, Leishmania donovani, Trypanosoma brucei and T. cruzi [21-26]. In a recent study, we reported that alkaloid hippeastrine showed specific activity against the latter and its amastigote form [23]. Now, with the aim to identify novel drug development starting points from natural products, we have screened a collection of 79 extracts from Amaryllidaceae plants for their anti-T. cruzi activity.

\section{Methods \\ Amaryllidaceae plant extracts}

Plants were collected and supplied under the framework of the CYTED BIFRENES project network (ref. 416RT0511). Alkaloids are the principal active constituent of Amaryllidaceae, and the extraction procedure explained below was devised to solely keep their alkaloid fraction. Unless otherwise indicated, alkaloid extracts were obtained from aerial parts or bulbs through acidbase extraction. Each species was collected and dried for 7 days at $40{ }^{\circ} \mathrm{C}$. Samples were ground and the powders macerated with methanol $(3 \times 100 \mathrm{~mL})$ at room temperature for 3 days. The mash was filtered and the organic solvent was taken to dryness under reduced pressure to obtain the crude extract. These extracts were acidified to $\mathrm{pH} 3$ with sulfuric acid ( $2 \%$, volume/volume $[\mathrm{v} / \mathrm{v}])$ in order to remove the neutral material with diethyl ether. Aqueous solutions were then basified up to $\mathrm{pH} 10$ with ammonium hydroxide $(25 \%, \mathrm{v} / \mathrm{v})$ to obtain the alkaloid extract with ethyl acetate. All alkaloid extracts were dried using reduced pressure. Dried material of each extract was solubilized with $100 \mu \mathrm{L}$ of dimethyl sulfoxide (DMSO) and used in the experiments. In all cases, the final DMSO percentage per well was below $0.5 \%$. The collection of alkaloid extracts is shown in Additional file 1: Table S1 and Additional file 2: Table S2.

\section{Host cell and T. cruzi parasite cultures}

Vero (green monkey kidney), LLC-MK2 (rhesus monkey kidney) and HepG2 (human liver) epithelial cells were cultured as described previously [23]. Mammalian infective stages of $T$. cruzi Tulahuen $\beta$-gal parasites (discrete typing unit VI) were maintained in LLC-MK2 cells and purified as previously described [27].

\section{Anti-T. cruzi primary assay}

The assay protocol followed has been described previously [23]. Briefly, Vero cells were diluted to $1 \times 10^{6}$ cells/ $\mathrm{mL}$. In parallel, isolated trypomastigotes were diluted at the same concentration, and both cell types mixed at a 1:1 ratio so that 50,000 Vero cells and 50,000 trypomastigotes were placed in each well (multiplicity of infection or $\mathrm{MOI}=1$ ) [23]. Before that, extracts had been poured into the assay plates at a starting volume of 2 or $1 \mu \mathrm{L}$, followed by further threefold dilution fashion. BNZ was used as positive control of drug growth inhibition, and each plate 
contained its own negative (Vero cells and parasites) and positive controls (trypomastigote forms alone) [23]. Plates were incubated for 4 days at $37{ }^{\circ} \mathrm{C}$ and the readout was made with chlorophenol red- $\beta$-D-galactoside (CPRG) substrate, as described previously [23, 28].

\section{Anti-T. cruzi amastigote assay}

As previously described [29], Vero cells were infected in bulk. They were seeded in T-175 flasks $\left(5 \times 10^{6}\right.$ cells/ flask) and cultured for $24 \mathrm{~h}$. Then, cells were washed with PBS, and free-swimming trypomastigotes $\left(1 \times 10^{7}\right.$ trypomastigotes per flask; MOI=1) were added for $18 \mathrm{~h}$. Infected cell monolayers were washed in PBS and detached from the flask. Cells were counted and diluted to a concentration of $5 \times 10^{5}$ cells $/ \mathrm{mL}$, before adding $100 \mu \mathrm{l}$ per well to test plates already containing the extracts. In all cases we included BNZ as control drug, and each plate contained its own negative (Vero cells and parasites) and positive controls (Vero cells) [29].

\section{Cell toxicity assays}

Vero and HepG2 cell toxicity assays were performed as described previously [23]. Briefly, cultures were washed with PBS, detached, and viability checked with Trypan blue before adding $100 \mu \mathrm{l}$ per well at the corresponding concentration [23]. All assay plates contained their own negative and positive controls [23,31]. Upon addition of biological reagents, they were incubated at $37{ }^{\circ} \mathrm{C}$ for 4 days (Vero) or 2 days (HepG2). AlamarBlue was used for assay readout, as described previously [23].

\section{Data analysis}

Absorbance and fluorescence values were normalized to the controls [30]. $\mathrm{IC}_{50}$ and $\mathrm{TC}_{50}$ values were determined with GraphPad Prism 7 software (version 7.00, 2016) using a non-linear regression analysis model [23]. Extracts $\mathrm{IC}_{50}$ and $\mathrm{TC}_{50}$ mean and standard deviation (SD) values are presented as parts per million (ppm) [32]. $\mathrm{IC}_{50}$ and $\mathrm{TC}_{50}$ values as ppm of the reference drugs $\mathrm{BNZ}$ and digitoxin (DTX) were calculated considering their average micromolar values and their respective molecular weights. Occasionally, $\mathrm{BNZ} \mathrm{IC}_{50}$ and $\mathrm{TC}_{50}$ values are provided as average micromolar values with their corresponding SD. In Additional file 1: Tables S1 and Additional file 2: Table S2 we also provide the $R^{2}$ fitadjustment of the extracts' dose-response curves.

\section{Results}

Anti-T. cruzi activity of extracts from Amaryllidaceae plants The collection of Amaryllidaceae extracts was screened using a phenotypic assay based on the parasite T. cruzi Tulahuen- $\beta$-gal and Vero cells as hosts [23]. In every run we included the reference drug BNZ as positive control of drug inhibition. Its mean $\mathrm{IC}_{50}$ was 1.55 (standard deviation, $\mathrm{SD}=0.05) \mu \mathrm{M}$ [i.e. $0.40(0.01) \mathrm{ppm}$ ] (Additional file 3: Figure S1A), which correlates with previously reported values $[23,27]$.

All extracts were tested at least in triplicate following a 1:3 dilution dose-response pattern to calculate their $\mathrm{IC}_{50}$ values. Extracts 51, 93, 97 and 117 showed the highest activity against $T$. cruzi with $\mathrm{IC}_{50}$ values between 1 and $2 \mathrm{ppm}$ (Additional file 1: Table S1). Since extracts are complex biological mixtures, we considered active those with $\mathrm{IC}_{50}$ values within a range $30 \times$ that of $\mathrm{BNZ}$. In agreement with this threshold, we identified 37 active (Additional file 1: Table S1) and 42 inactive extracts (Additional file 2: Table S2).

\section{Identification of extracts with specific activity against the parasite}

In order to ascertain whether retrieved anti- $T$. cruzi activity was indeed specific against the parasite, and to discard any extracts that were toxic to the host cells instead, we performed a secondary cell toxicity assay on Vero cells. BNZ was included in every run as reference, and its average $\mathrm{TC}_{50}$ was $267.5(14.38) \mu \mathrm{M}$ [i.e. 69.6 (3.74) ppm] (Additional file 3: Figure S1A), correlating with previously reported values $[23,30]$.

Twelve out of 37 extracts were less toxic to Vero cells than BNZ (Additional file 1: Table S1). Extracts 24, 56, 81 and 101 had the highest $\mathrm{TC}_{50}$ to Vero cells, with values ranging from 211.5 to $346.7 \mathrm{ppm}$ (Additional file 1: Table S1). We established a selectivity index cut-off of $20 \times \mathrm{TC}_{50} / \mathrm{IC}_{50}(\mathrm{SI}>20)$, twice the ratio considered elsewhere, to progress compounds with specific anti-parasitic activity [31]. As a result, the activity of seven of the active extracts was determined as specific against the parasite (Fig. 1). Their dose-response activity curves against T. cruzi and Vero cells are shown in Fig. 2.

Remarkably, three of the extracts showed a $\mathrm{TC}_{50} / \mathrm{IC}_{50}$ ratio higher than 30 , wherein extracts 24 and 81 presented the highest selective anti- $T$. cruzi activity, with SI values $>37$ (Table 1). Among the extracts that showed specific activity against the parasite, those from genera Rhodophiala and Crinum predominated over the rest, with two extracts per genus (Fig. 3).

\section{HepG2 cell toxicity assay}

In order to anticipate potential liver toxicity in humans, we assessed the toxicity of those seven selected T. cruzispecific extracts against the human cell line HepG2 [33, 34]. In this case, we included the reference drugs BNZ and DTX in every plate, which respectively showed average $\mathrm{TC}_{50}$ values of $197.8(28.4) \mu \mathrm{M}$ and $0.19(0.06) \mu \mathrm{M}$ [i.e. 51.47 (7.39) ppm and 0.14 (0.046) ppm] (Additional file 3: Figure S1B, C). Contrary to what was observed 


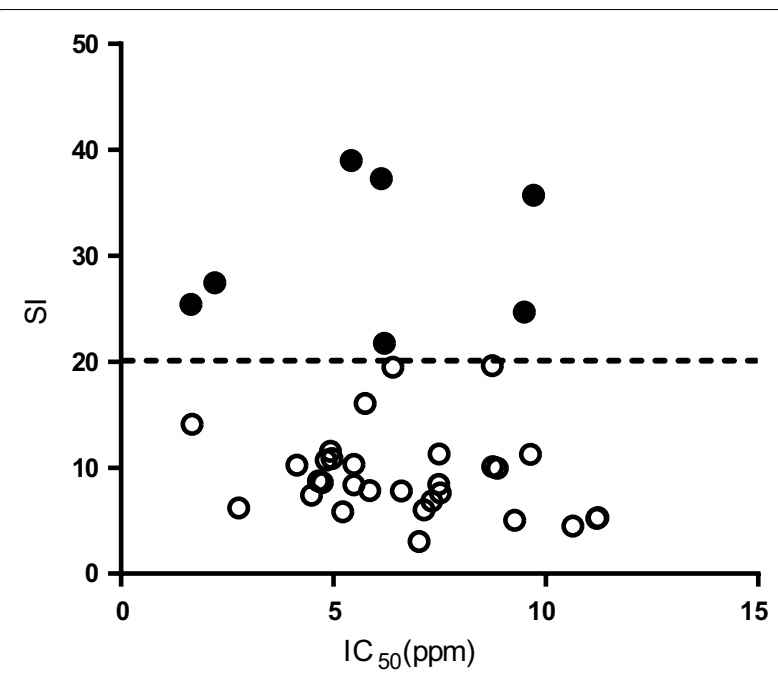

Fig. 1 Distribution of active extracts according to their $I_{50}$ and $\mathrm{SI}$ values. Parasite-selective extracts are represented by filled circles and non-selective extracts by empty circles. Horizontal dashed line indicates the threshold of $\mathrm{SI}>20$

on Vero cell toxicity assay, toxicity of the extracts to HepG2 cells was lower than what was retrieved for BNZ (Table 1). Extract 23, however, showed a SI value $<20$, and it was discarded from further progression. In contrast, extracts 51, 56 and 101 showed SI values $>70$ due to their potent anti-T. cruzi activity and low toxicity (Table 1).

\section{Anti-amastigote activity of specifically active extracts}

Amastigotes are likely the main target for any prospective drug to treat chronic T. cruzi infections. Thus, we evaluated the activity of the six extracts that were specific (SI $>20$ ) against T. cruzi and non-toxic to HepG2 cells by means of a biological assay specifically targeting the mammalian replicative form of the parasite. We included the reference drug BNZ in each assay round, registering an average $\mathrm{IC}_{50}$ value of $2.02(0.09) \mu \mathrm{M}$ [or $0.53(0.02)$ $\mathrm{ppm}]$. Generally, we found that all the extracts were less potent against the amastigote form than BNZ (Table 1). According to the threshold of $\mathrm{IC}_{50}<30 \times$ that of $\mathrm{BNZ}$, we selected two extracts (Table 1). Both had anti-amastigote SI values $>20$ with respect to Vero cells and were not toxic to HepG2 cells (Fig. 4).

\section{Discussion}

Anti-protozoal properties of Amaryllidaceae extracts, or alkaloids purified from them, have been evaluated before [21-26], but this is to the best of our knowledge the largest screening of a collection of extracts derived from plants of this family against a parasite pathogen. Upon screening of 79 extracts against T. cruzi, we found 37 active and 42 inactive extracts in the primary anti-parasitic assay. All extracts from genus Ismene were inactive, while all from genera Eucharis, Hymenocallis and Pyrolirion were initially active. Distinct anti-T. cruzi activities were retrieved with extracts from other genera, depending on the part of the plant processed. Variations in the alkaloid composition of different parts of the plant within the same species is explained by ontogenetic (seasonal) variability, as Amaryllidaceae alkaloids can vary among tissues during the plants' biological cycle [15]. In general, extracts obtained upon processing bulbs displayed higher activity against the parasite than those obtained from aerial parts or flowers. In fact, 29 out of the 37 active extracts were obtained from bulbs.

Active extracts showed a range of $\mathrm{IC}_{50}$ values between 1.65 and $11.23 \mathrm{ppm}(\leq 30 \times$ that of $\mathrm{BNZ})$ and all were progressed onto the secondary Vero cell toxicity assay to determine their SI. Only seven extracts had a SI $>20$, and a subsequent HepG2 cell assay determined that six had toxicity to HepG2 cells that was at least 20-fold lower than that against the parasite (Table 1). The observation that extracts were generally less toxic to HepG2 cells than to Vero cells is likely related to the exposure time of 2 or 4 days in the corresponding assays. Ultimately, just two out of those six displayed specific anti-amastigote activity $(\mathrm{SI}>20)$ : one from Rhodophiala andicola (number 24) and another from Crinum erubescens (number 56). Among the extracts that did not display specific antiamastigote activity, some had been previously studied against T. cruzi and their alkaloid composition deciphered. For example, extract 51 from Amaryllis belladonna bulbs collected in Chile had the most potent $\mathrm{IC}_{50}$ value of all $\left(\mathrm{IC}_{50}=1.65 \mathrm{ppm}\right)$ and yielded SI rates of 25.43 and 77.69 against Vero and HepG2 cells (Table 1). A former study identified 26 different alkaloids in bulb samples from that species collected in Brazil and isolated three of them (1-O-acetylcaranine, 3-O-acetylhamayne and buphanamine) [22]. In vitro anti-protozoal assays revealed that the higher anti-T. cruzi activity was provided by 3-O-acetylhamayne despite its toxicity to L6 cells [22], and the same study reported that the crude extract was less toxic $\left(\mathrm{TC}_{50}=34.3 \mu \mathrm{g} / \mathrm{mL}\right)$ than the alkaloid itself [22]. Expecting higher toxicity of isolated alkaloid species to parasites and host cells, we determined a SI threshold $>20$ in the primary anti-parasitic screening, which is double what has been used in other studies [23, 30].

Regarding the two selected extracts, number 56 exhibited the sixth most potent anti-parasitic activity in the primary assay $\left(\mathrm{IC}_{50}=9.50 \mathrm{ppm}\right)$, and the second most potent against the amastigote form $\left(\mathrm{IC}_{50}=11.10 \mathrm{ppm}\right)$, highlighting its wide SI windows versus HepG2 cells ( $\mathrm{SI}=71.4$ and 61.1 , for the primary and anti-amastigote assays respectively). Notably, lower 

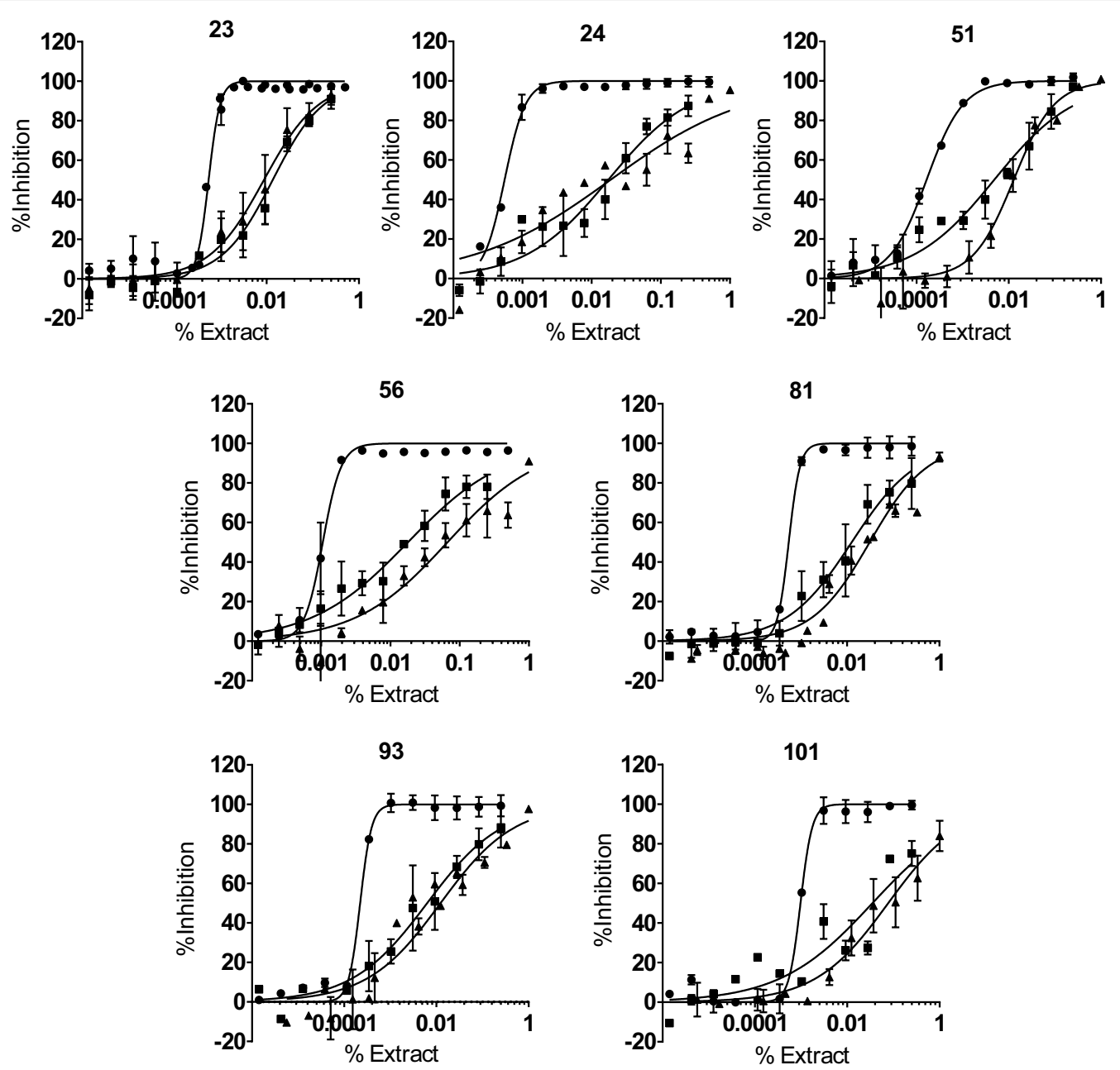

Fig. 2 Dose-response curves of selected extracts based on the specificity of their anti-parasitic activity. Anti-T. cruzi activity data are represented by circles, Vero cell toxicity data by squares, and HepG2 cell toxicity data by triangles. Graphs represent mean results and SD of at least three independent biological replicates [23, 24]

toxicity against Vero cells was observed with extract 56 obtained from bulbs in comparison to extract 82 from the same plant and site but processed from aerial parts. In relation to that, Rojas-Vera and co-workers found that the quantity of lycorine-type alkaloids was higher in bulbs from C. erubescens (collected in Venezuela) while non-identified alkaloids were higher in leaves [35]. It has been described that lycorine extracted from Narcissus species had an $\mathrm{IC}_{50}=0.7 \mu \mathrm{M}$ against $T$. cruzi but was not parasite-specific [23], which may suggest the presence of other alkaloids in extract 56 that are responsible for its registered anti-parasitic capacity. Notably, C. erubescens bulbs collected in Venezuela (extract number 83) had higher toxicity to Vero cells than extract 56, which could be due to variation in alkaloids among the same plants collected from different locations [18].
The alkaloid profile and anti-acetylcholinesterase activity of extracts from Rhodophiala species collected in Chile have been reported in previous studies [18]. Here we present for the first time results of its anti-T. cruzi properties. Some Rhodophiala species have been described as a rich source of lycorine, and haemanthamine/crinine- and tazettine-type alkaloids [18], which are some of the alkaloids that have shown activity against $T$. cruzi before $[21,23]$. Herein, an aerial parts extract from $R$. andicola collected in Chile (extract number 24) had an $\mathrm{IC}_{50}$ value of $6.13 \mathrm{ppm}$ in the primary assay and the most potent activity against amastigotes of all extracts tested $\left(\mathrm{IC}_{50}=10.18 \mathrm{ppm}\right)$, achieving good SI values. The alkaloid profile of this extract has been described by Tallini and co-workers, showing high quantities of tazettine and other non-identified type alkaloids [18]. The extract obtained upon processing the bulbs of 


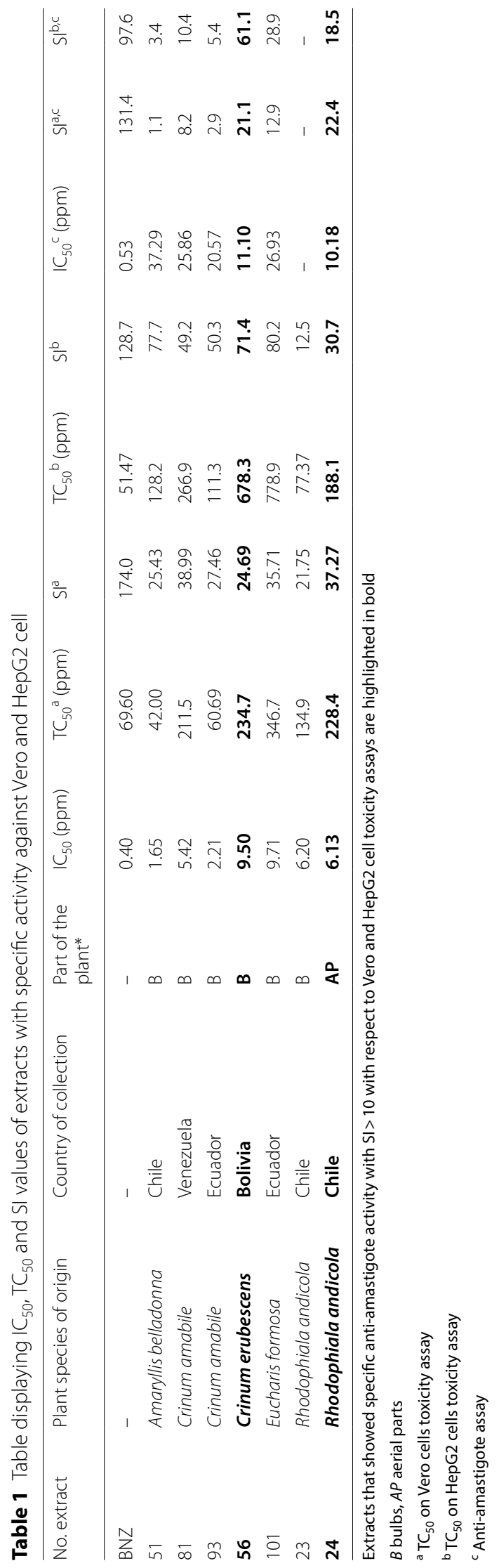




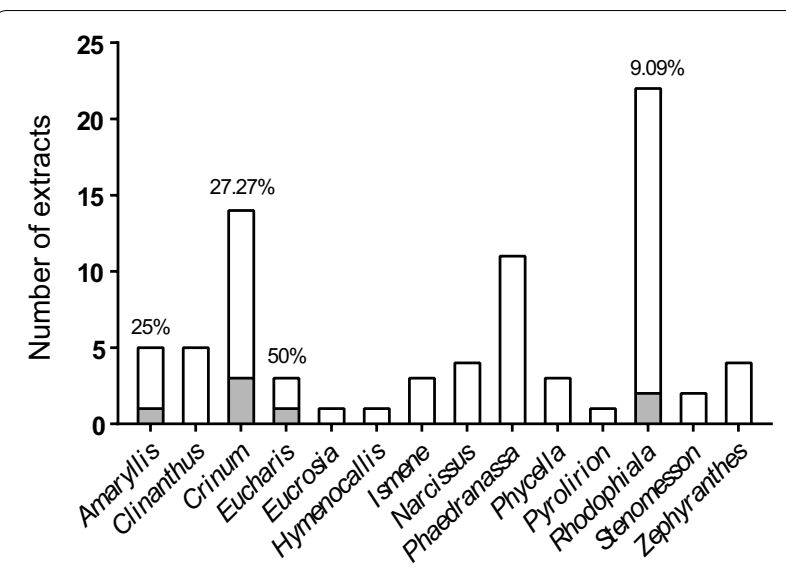

Fig. 3 Distribution of anti-T. cruzi selective extracts per plant genus. Percentage was calculated as the number of selective extracts (represented in grey) over the total number of extracts within each genus further investigated. Upon identifying these alkaloids, specifically evaluating them against the $T$. cruzi Tulahuen $\beta$-galactosidase strain, as well as other parasite strains, with orthogonal anti-parasitic assays (e.g. imaging assays) will be of relevance for their progress in the drug discovery pathway [30]. Although there is little information on the structure-activity relationships (SAR) of Amaryllidaceae-derived alkaloids, some results suggest that the methylenedioxy group and the presence of a tertiary nitrogen without a methyl group can contribute to increasing their anti-parasitic activity [36]. Identification and functional characterization of any new alkaloids would widen current SAR knowledge, helping guide chemical modification to obtain higher potency and specific anti-parasitic outputs. Despite the difficulties and high attrition rates expected, the anti- $T$. cruzi activity rates reported in this work allow us to be optimistic and encourage further studies.

this species (number 23) showed higher toxicity against both mammalian cell lines, resulting in SI values $<20$, which might be explained by higher content of lycorine and haemanthamine/crinine type alkaloids [18].

Whether already known alkaloids or newly identified ones are responsible for the anti- $T$. cruzi activity observed in the two selected extracts will need to be
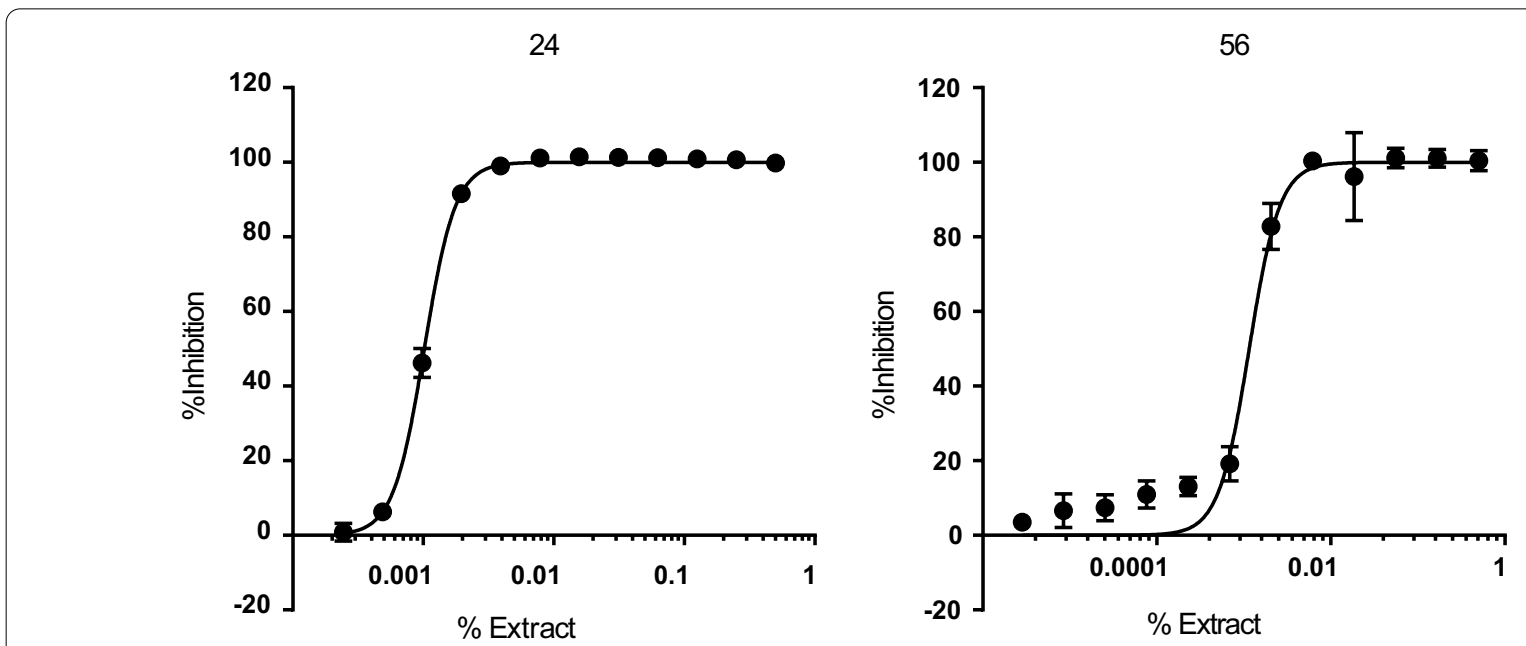

Fig. 4 Dose-response curves of the extracts that had specific ( $\mathrm{SI}>10)$ anti-amastigote activity. Graphs represent mean results and SD of at least three replicates $[23,24$, etc.] 


\section{Supplementary Information}

The online version contains supplementary material available at https://doi. org/10.1186/s13071-021-04837-9.

Additional file 1: Table S1. Active extracts IC50, TC50 and SI parameters are shown for each extract. IC50 and TC50 R2 statistical indicator is also included in the table. Those extracts that presented specific activity (SI > 20) are highlighted in grey.

Additional file 2: Table S2. Inactive extracts IC50 values and their R2 curve adjustment indicator are included.

Additional file 3: Figure S1. Dose response curves of standard drug BNZ and DTX. (A) Anti-T. cruzi assay (circles), anti-amastigote assay (triangles) and Vero cell toxicity assay (squares) of BNZ. (B) HepG2 cell toxicity assays of BNZ and (C) DTX, respectively.

\section{Acknowledgements}

We are grateful to Fred Buckner (University of Washington, Seattle, USA) for kindly providing T. cruzi parasites from the Tulahuen strain (DTU VI) expressing $\beta$-galactosidase. Authors thank investigators in the BIFRENES - CYTED network (416RT0511) for providing plant material, in particular: Giovanna Almanza Vega (Universidad Mayor de San Andrés, Bolivia), Warley de Souza Borges (Universidade Federal do Espírito Santo, Brazil), José Angelo Silveira Zuanazzi (Universidad Federal de Río Grande do Sul, Brazil), Guillermo Schmeda Hirschmann (Universidad de Talca, Chile), Edison Javier Osorio Durango (Universidad de Antioquía, Colombia), Fabio Antonio Cabezas Fajardo (Universidad del Cauca, Colombia), Karen Acosta León (Escuela Superior Politécnica de Chimborazo, Ecuador), Nora Oleas Gallo (Universidad Tecnológica Indoamérica, Ecuador), Ricardo Reyes-Chilpa (Universidad Nacional Autónoma de México, Mexico), Mario Hibert Huaylla Limachi (Universidad Nacional de Moquegua, Peru), Marilú Roxana Soto Vásquez (Universidad Nacional de Trujillo, Perú), Janne Rojas Vera (Universidad de Los Andes, Venezuela).

\section{Authors' contributions}

NMP, NCS, JB, MJP, JG and JAP conceptualized the study; NMP performed all biological assays; NCS helped with the assays; LRT and JB obtained the extracts; MJP and JG provided funds; NMP and JAP wrote the article. All authors read and approved the final manuscript.

\section{Funding}

We thank the support by the Departament d'Universitats i Recerca de la Generalitat de Catalunya, Spain (AGAUR; 2017SGR00924), and the funding by the Instituto de Salud Carlos III RICET Network for Cooperative Research in Tropical Diseases (ISCIII; RD12/0018/0010) and FEDER. JAP was initially funded by a Juan de la Cierva-Incorporación contract from the Spanish Science Ministry. The work of NMP, NCS and JG is supported by the Spanish Ministry of Science and Innovation-ISCIII project PI18/01054. LRT and JB (UB research group 2017SGR604) thank CYTED (416RT0511) for financial support. LRT is thankful to CAPES (Coordenação de Pessoal de Nível Superior) for the doctoral fellowship (Processo 13553135). MJP's research is supported by the Ministry of Health, Government of Catalunya (PERIS 2016-2010 SLT008/18/00132). We also acknowledge support from the Spanish Ministry of Science, Innovation and Universities through the "Centro de Excelencia Severo Ochoa 2019-2023" Program (CEX2018-000806-S), and support from the Generalitat de Catalunya through the CERCA Program.

\section{Availability of data and materials}

Data and materials can be made available upon reasonable request to the authors.

\section{Declarations}

Ethics approval and consent to participate Not applicable.

\section{Consent for publication}

Not applicable.

\section{Competing interests}

The authors declare no competing interests.

\section{Author details}

${ }^{1}$ Barcelona Institute for Global Health (ISGlobal), Hospital Clinic-University of Barcelona, 08036 Barcelona, Spain. ${ }^{2}$ Departament de Biologia, Sanitat i Medi Ambient, Facultat de Farmàcia I Ciències de L'Alimentació, Universitat de Barcelona, 08028 Barcelona, Spain. ${ }^{3}$ Graduate Program in Pharmaceutical Sciences, Federal University of Rio Grande Do Sul, Porto Alegre - RS 90610-000, Brazil.

Received: 16 December 2020 Accepted: 9 June 2021

Published online: 26 June 2021

\section{References}

1. WHO: Chagas disease (American trypanosomiasis). https://www.who.int/ en/news-room/fact-sheets/detail/chagas-disease-(american-trypanosom iasis). Accessed 16 Nov 2020.

2. Pinazo MJ, Gascon J. Chagas disease: from Latin America to the world. Reports Parasitol. 2015;4:7-14.

3. Prata A. Clinical and epidemiological aspects of Chagas disease. Lancet Infect Dis. 2001;1:92-100.

4. Alonso-Padilla J, Cortes-Serra N, Pinazo MJ, Botazzi ME, Abril M, Barreira $\mathrm{F}$, et al. Strategies to enhance access to diagnosis and treatment for Chagas disease patients in Latin America. Exp Rev Anti Infect Ther. 2019;17:145-57.

5. Buckner FS, Waters NC, Avery VM. Recent highlights in anti-protozoan drug development and resistance research. Int J Parasitol Drugs Drug Resist. 2012:2:230-5.

6. Chatelain E. Chagas disease drug discovery: toward a new era. J Biomol Screen. 2015;20:22-35.

7. Deeks ED. Fexinidazole: first global approval. Drugs. 2019;79:215.

8. Stein C, Migliavaca CB, Colpani V, da Rosa PR, Sganzerla D, Giordani NE, et al. Amiodarone for arrhythmia in patients with Chagas disease: a systematic review and individual patient data meta-analysis. PLoS Negl Trop Dis. 2018;8:e0006742

9. Martínez-Peinado N, Cortes-Serra N, Losada-Galvan I, Alonso-Vega C, Urbina JA, Rodriguez A, et al. Emerging agents for the treatment of Chagas disease: what is in the preclinical and clinical development pipeline? Expert Opin Investig Drugs. 2020;29:947-59.

10. Lee ML, Schneider G. Scaffold architecture and pharmacophoric properties of natural products and trade drugs: application in the design of natural product-based combinatorial libraries. J Comb Chem. 2001;3:284-9.

11. Schmidt TJ, Khalid SA, Romanha AJ, Alves TM, Biavatti MW, Brun R, et al. The potential of secondary metabolites from plants as drugs or leads against protozoan neglected diseases_-part I. Curr Med Chem. 2012;19:2128-75.

12. Schmidt TJ, Khalid SA, Romanha AJ, Alves TM, Biavatti MW, Brun R, et al. The potential of secondary metabolites from plants as drugs or leads against protozoan neglected diseases - part II. Curr Med Chem. 2012;19:2176-228.

13. Newman DJ, Cragg GM. Natural products as sources of new drugs from 1981 to 2014. J Nat Prod. 2016;79:629-61.

14. Izumi E, Ueda-Nakamura T, Dias Filho BP, Veiga Júnior VF, Nakamura CV. Natural products and Chagas' disease: a review of plant compounds studied for activity against Trypanosoma cruzi. Nat Prod Rep. 2011;28:809-23.

15. Bastida J, Lavilla R, Viladomat F. Chemical and biological aspects of Narcissus alkaloids. Alkaloids Chem Biol. 2006;63:87-179.

16. Berkov S, Osorio E, Viladomat F, Bastida J. Chemodiversity, chemotaxonomy and chemoecology of Amaryllidaceae alkaloids. Alkaloids Chem Biol. 2020;83:113-85.

17. Takos AM, Rook F. Towards a molecular understanding of the biosynthesis of Amaryllidaceae alkaloids in support of their expanding medical use. Int J Mol Sci. 2013;14:11713-41.

18. Tallini LR, Bastida J, Cortes N, Osorio EH, Theoduloz C, SchmedaHirschmann G. Cholinesterase inhibition activity, alkaloid profiling and molecular docking of Chilean Rhodophiala (Amaryllidaceae). Molecules. 2018:23:1532 
19. Tallini LR, Torras-Claveria L, de Souza WB, Kaiser M, Viladomat F, Zuanazzi J, et al. N-oxide alkaloids from Crinum amabile (Amaryllidaceae). Molecules. 2018;23:1277.

20. Sramek JJ, Frackiewicz EJ, Cutler NR. Review of the acetylcholinesterase inhibitor galanthamine. Expert Opin Investig Drugs. 2000;9:2393-402.

21. Nair JJ, Staden J. Antiprotozoal alkaloid principles of the plant family Amaryllidaceae. Bio Med Chem Lett. 2019;29:126642.

22. Tallini LR, de Andrade JP, Kaiser M, Viladomat F, Nair JJ, Zuanazzi JAS, et al. Alkaloid constituents of the Amaryllidaceae plant Amaryllis belladonna L. Molecules. 2017;22:1437.

23. Martínez-Peinado N, Cortes-Serra N, Torras-Claveria L, Pinazo MJ, Gascon J, Bastida J, et al. Amaryllidaceae alkaloids with anti-Trypanosoma cruzi activity. Parasit Vectors. 2020;13:299.

24. Labraa J, Machocho AK, Kricsfalusy V, Brun R, Codina C, Viladomat F, et al. Alkaloids from Narcissus angustifolius subsp. transcarpathicus (Amaryllidaceae). Phytochemistry. 2002;60:847-52

25. Toriizuka Y, Kinoshita E, Kogure N, Kitajima M, Ishiyama A, Otoguro K, et al. New lycorine-type alkaloid from Lycoris traubii and evaluation of antitrypanosomal and antimalarial activities of lycorine derivatives. Bioorganic Med Chem. 2008;16:10182-9.

26. Kaya Gl, Sarikaya B, Onur MA, Somer NU, Viladomat F, Codina C, et al. Antiprotozoal alkaloids from Galanthus trojanus. Phytochem Lett. 2011;4:301-5

27. Buckner FS, Verlinde CL, La Flamme AC, Van Voorhis WC. Efficient technique for screening drugs for activity against Trypanosoma cruzi using parasites expressing $\beta$-galactosidase. Antimicrob Agents Chemother. 1996;40:2592-7.

28. Bettiol E, Samanovic M, Murkin AS, Raper J, Buckner F, Rodriguez A. Identification of three classes of heteroaromatic compounds with activity against intracellular Trypanosoma cruzi by chemical library screening. PLoS Negl Trop Dis. 2009;3:e384.

29. Martinez-Peinado N, Martori C, Cortes-Serra N, Sherman J, Rodriguez A, Gascon J, et al. Anti-Trypanosoma cruzi activity of metabolism modifier compounds. Int J Mol Sci. 2021;22:688.
30. Alonso-Padilla J, Cotillo I, Presa JL, Cantizani J, Peña I, Bardera Al, et al. Automated high-content assay for compounds selectively toxic to Trypanosoma cruzi in a myoblastic cell line. PLoS Negl Trop Dis. 2015;9:e0003493.

31. Peña I, Pilar Manzano M, Cantizani J, Kessler A, Alonso-Padilla J, Bardera Al, et al. New compound sets identified from high throughput phenotypic screening against three kinetoplastid parasites: an open resource. Sci Rep. 2015;5:8771.

32. Yerbanga RS, Lucantoni L, Ouédraogo RK, Da DF, Yao FA, Yaméogo KB, et al. Transmission blocking activity of Azadirachta indica and Guiera senegalensis extracts on the sporogonic development of Plasmodium falciparum field isolates in Anopheles coluzzii mosquitoes. Parasit Vectors. 2014;7:185.

33. Choi JM, Oh SJ, Lee SY, Im JH, Oh JM, Ryu CS, et al. HepG2 cells as an in vitro model for evaluation of cytochrome $\mathrm{P} 450$ induction by xenobiotics. Arch Pharm Res. 2015;38:691-704.

34. Crouch SP, Kozlowski R, Slater KJ, Fletcher J. The use of ATP bioluminescence as a measure of cell proliferation and cytotoxicity. J Immunol Methods. 1993;160:81-8.

35. Rojas-Vera JC, Buitrago-Díaz AA, Possamai LM, Timmers LFSM, Tallini LR Bastida J. Alkaloid profile and cholinesterase inhibition activity of five species of Amaryllidaceae family collected from Mérida state-Venezuela. South African J Bot. 2021;136:126-36.

36. Tallini LR, Osorio EH, Dos Santos VD, de Souza BW, Kaiser M, Viladomat F, et al. Hippeastrum reticulatum (Amaryllidaceae): alkaloid profiling, biological activities and molecular docking. Molecules. 2017;22:2191.

\section{Publisher's Note}

Springer Nature remains neutral with regard to jurisdictional claims in published maps and institutional affiliations.
Ready to submit your research? Choose BMC and benefit from:

- fast, convenient online submission

- thorough peer review by experienced researchers in your field

- rapid publication on acceptance

- support for research data, including large and complex data types

- gold Open Access which fosters wider collaboration and increased citations

- maximum visibility for your research: over 100M website views per year

At BMC, research is always in progress.

Learn more biomedcentral.com/submissions 